\title{
Political inequality, political participation, and support for populist parties
}

\section{Kim Leonie Kellermann ${ }^{1}$ (D)}

Accepted: 4 December 2021 / Published online: 17 December 2021

(c) The Author(s) 2021

\begin{abstract}
We theoretically investigate how political abstention among certain social groups encourages populist parties to enter the political stage, trying to absorb inactive voters. We design a two-stage game with two established parties and $n$ voters who jointly determine a taxation policy. The electorate is divided into two groups, the advantaged and the disadvantaged. Voters' decisions on whether to participate depend on a party's tax rate proposal and on general party ideology. Effective political participation requires a certain amount of financial, social and intellectual resources to, for example, evaluate party programs or to engage in political discussion. As the disadvantaged are endowed with fewer resources, they lack political efficacy, resulting in less political participation. Consequently, the established parties propose a tax rate which is biased towards the preferences of the advantaged. The unused voter potential among the disadvantaged draws the interest of a populist challenger. To win support from the disadvantaged, the challenger party optimally proposes a respectively biased tax rate, which then works to polarize the political spectrum.
\end{abstract}

Keywords Populist parties · Political participation · Political inequality · Probabilistic voting

JEL Classification D63 - D71 $\cdot$ D72 $\cdot$ C72

\begin{abstract}
The author wishes to thank Roger Congleton, two anonymous reviewers, Thomas Apolte, Celeste Brennecka, Julie Davies, Lena Gerling, Verena Löffler, Manuel Santos Silva, Simon Winter, Arthur Zillante, and seminar participants at George Mason University for valuable comments. The paper benefited from fruitful discussions at the $2^{\text {nd }}$ PEDD Conference, the 2018 PCS Annual Meeting, the 2018 EPCS Conference, the 2020 EEA Virtual and the 2020 VfS Annual Meeting. Niklas Pieper and Camilla Nienhaus provided valuable research assistance.
\end{abstract}

Kim Leonie Kellermann

kim.kellermann@wiwi.uni-muenster.de

1 Center for Interdisciplinary Economics, University of Münster, Scharnhorststraße 100, 48151 Münster, Germany 


\section{Introduction}

Disenchanted citizens have two options for expressing their discontent with politics, exit or voice (Hirshman 1970). Considering electoral abstention as a very simple form of exiting political decision-making, this behavior has been empirically shown to be more widespread among individuals of lower socio-economic status. In the literature, one explanation is that disadvantaged voters have fewer politically valuable resources such as monetary income, educational attainment, or political networks (Brady et al. 1995). This shortage makes it harder for the disadvantaged to collect and evaluate political information, to communicate their preferences to policymakers and to effectively shape the political process. Feeling neglected by political parties, the disadvantaged choose to abstain from public decision-making (Goodin and Dryzek 1980; Emmenegger et al. 2015; Han 2016; Gerber et al. 2011; Solt 2015; Guiso et al. 2018; Rico et al. 2020; Guiso et al. 2020; Roemer 1998).

However, alienated voters may be encouraged to engage again if given a political alternative, which explicitly addresses their capabilities. In that sense, it has been observed that the ever-rising radical and populist forces in established democracies are relatively more successful among socially underprivileged voters (Han 2016; Emmenegger et al. 2015; Rooduijn 2017; Oesch 2008; Georgiadou et al. 2018; Guiso et al. 2018; Gethin et al. 2021; Gest et al. 2017; Burgoon et al. 2018; Hobolt 2016; Guiso et al. 2020; Schulte-Cloos and Leininger 2021). Not only are these parties' manifestos characterized by promising future social security, but populist platforms are also designed to be more easily accessible. Approachable political candidates present themselves as common people who therefore understand the common person's worries and hardships. Political solutions are characterized by tempting simplicity and clarity, for instance when right-wing populist parties claim that poverty, unemployment or crime, could all quickly be solved by simply stopping immigration (Mudde 2004, 2013; Golder 2003; Durante et al. 2019).

Linking these observations, we raise the question of whether abstention caused by political inequality promotes the political market entry of populist parties (Rico et al. 2020; Mudde 2013; Immerzeel and Pickup 2015; Guiso et al. 2018; Rodrik 2018). To this end, we develop a theoretical illustration showing how inequalities in political efficacy across social groups impinge on political involvement and encourage populist parties to step in and absorb the alienated. We extend the well-established probabilistic voting model as originally introduced in Lindbeck and Weibull (1987) to design a simple two-stage game with citizens and parties jointly determining a policy outcome. All citizens provide support, in terms of votes, for one of two established parties in return for a future policy realization, here a tax rate. Citizens are divided into two groups, the advantaged and the disadvantaged, who have conflicting opinions regarding optimal taxation. We assume that the two groups of voters are politically unequal in the sense that they are unequally endowed with the resources necessary to effectively partake in the political process. Among these are financial means, civic skills and social 
networks as well as political, economic or legal expertise. The disadvantaged are endowed with fewer of these resources, which makes it harder for them to evaluate political programs, get involved in political discussion or assess candidates' abilities. Therefore, the disadvantaged are less likely to participate in political decision making. In contrast, the advantaged constitute a more attractive target group for support-maximizing parties which converge to an equilibrium policy level that is biased towards the preferences of the advantaged. This strategy stimulates involvement among the advantaged, while lowering involvement among the disadvantaged, resulting in an over-representation of the former.

The unused support from the disadvantaged then draws the interest of a populist party, whose platform is characterized by simple political messages, a less elaborate organizational structure and a greater potential for disenchanted voters to identify with political candidates (Mudde 2004, 2013). This style particularly appeals to the disadvantaged as it is able to partly compensate for their political efficacy shortage. To secure their support, the populist party ideally proposes a tax rate which leans towards the interests of the disadvantaged. However, if resource endowment and, thereby, political efficacy of the disadvantaged fall below a critical level, addressing and mobilizing these voters will not pay off for any party.

Our contribution to the existing literature is threefold. First, we extend the economic theory of voting to highlight the role of unequal participation conditions. Unlike many previous approaches, we do not limit our analysis to one side of the political market but illustrate the mutual feedback effects of political supply and demand. Second, we provide a theoretical underpinning for the interdependence of political inequality, party capture and party system changes. Therefore, our contribution to the related literature implies an all-encompassing theorization of the aforementioned empirical observations. In that sense, our approach is in line with a growing number of theoretical studies investigating the relation between social identity, inequality and populism (Guiso et al. 2018; Gethin et al. 2021; Pastor and Veronesi 2021; Grossman and Helpman 2021; Bonomi et al. 2021; Guiso et al. 2020). Third, we engage with the scientific discussion of the most recent emergence of populist movements and add to the understanding of strategies they may use to win alienated groups. Thus, we propose that political inequality and the resulting abstention serve as one explanation for the emergence of populist parties.

The question of how socio-economic advantage translates into the capture of political agents has mainly focused on the role of (wealthy) interest groups (among others Grossman and Helpman 1994; Holcombe 2015; Acemoglu and Robinson 2008; Lai 2010; Winter 2017; Lohmann 1995; Drazen et al. 2007). However, Gilens and Page (2014) state that public decision-making is generally dominated by wellendowed citizens, even in the absence of formally organized interest. Not only do economic elites have the financial means, but they also have the networks and positions to influence policymakers. The authors refer to this phenomenon as economic elite domination and provide tentative evidence that the advantaged are in fact more successful at having their preferred policies implemented. Stadelmann et al. (2015) as well as Krieger and Meierrieks (2016) empirically confirm these findings. Accordingly, the literature suggests a positive relationship between individual voters' monetary resources and their political leverage. 
Financial endowment may serve as a proxy for general politically valuable resources which determine political involvement (Jesuit et al. 2009; Han 2016; Gallego 2010; Rydgren 2007; Solt 2008). As outlined by Brady et al. (1995) in their seminal resource theory, active and effective involvement in public decision-making requires the use of time and civic skills, which comprise oral and written communication skills, organizational abilities and educational attainment, as well as the strength of social or political networks and interpersonal trust. It is through these skills that citizens are able to successfully draw the attention of policymakers to their situation and have their issues put onto the political agenda. In addition, most political candidates in established democracies belong to the upper social classes. Thus, there is a high likelihood that policymakers and voters of the same socioeconomic background will identify with each other and have personal ties. In the political science literature in particular, this group of political capabilities is referred to by political efficacy, which tends to be lower among the disadvantaged, entailing fewer incentives to partake in public decision-making (Emmenegger et al. 2015; Rico et al. 2020). In line with this, a substantial body of empirical research provides evidence of a negative relationship between income inequality and aggregate-level voter turnout. Those at the bottom end of the income distribution are relatively more likely not to identify with policymakers and, therefore, abstain from the political process (Stockemer and Scruggs 2012; Geys 2006; Jensen and Bøgeskov Jespersen 2017; Bouvet and King 2016; Pontusson and Rueda 2010; Kelly and Enns 2010; Solt 2010, 2008; Myatt 2017; Kselman and Niou 2011; Rooduijn et al. 2016; Solt 2015; Georgiadou et al. 2018; Guiso et al. 2018, 2020; Roemer 1998).

Our model setup highlights the resulting rationale of support-maximizing parties. As they need votes to win public office, they cater to the preferences of citizens that are more likely to turn out to vote (Lindbeck and Weibull 1987; Persson and Tabellini 2002). This programmatic focus on the advantaged further stimulates political alienation of the disadvantaged. Several case studies feature corresponding evidence where parties lose support of an underprivileged electorate because of policies which disproportionately benefit upper social classes (Eichhorst and Marx 2011; Lindvall and Rueda 2013; Karreth et al. 2012). In line with this, the most recent wave of populist parties, especially in Europe, reject clique politics, elite enrichment and the under-representation of the common people, which they claim is a defining feature of current politics (Mudde 2013; Rico et al. 2020; Rooduijn 2017; Noury and Roland 2020). Thus, in a final step, our model explains the emergence of such a populist party in relation to political alienation. As the abstention rate increases, the unused voter potential also grows. A populist party seeks to enter the political stage to sway the abstaining. This type of party suggests a certain closeness to politically alienated groups and enables participation at relatively low effort. Unlike its competitors, the populist party has an incentive to propose a tax rate which is in line with the preferences of the disadvantaged (Congleton and Steunenberg 1998). It wins over the politically inactive citizens (Immerzeel and Pickup 2015; Rydgren 2007; Lubbers et al. 2002; Schulte-Cloos and Leininger 2021), who switch from exit to voice.

The remainder of this paper is organized as follows. Section 2.1 presents the model framework and illustrates how the disadvantaged are alienated from politics 
as a consequence of political inequality. In Sect. 2.2, we outline the resulting emergence of a populist party. Furthermore, we highlight the reactions of the parties to different levels of political inequality among voters. Section 3 concludes.

\section{Model setup}

\subsection{Political outcomes with political inequality}

Our basic setup closely follows the well-established probabilistic voting model as developed by Lindbeck and Weibull (1987). Some of the setting and results also resemble those in Congleton and Steunenberg (1998), but with a different focus on the emergence of challenger parties here. We consider an economy with $n$ citizens who are all entitled voters. The electorate is divided into two groups $g \in\{a, d\}$. A number of $n_{a}$ citizens belong to the advantaged and $n_{d}=n-n_{a}$ citizens belong to the disadvantaged. Our understanding of these terms is rather broad. In some cases, the advantaged may represent a very small, privileged group, where the disadvantaged are the mass of the general population. In other cases, however, the two groups may rather refer to above- and below-median income earners, respectively. The groups differ with respect to two features: their political efficacy and their policy preferences.

In regards to the first feature, each citizen $i$ is endowed with a quantity of politically valuable resources $r_{g}$. By this term, we refer to assets that are necessary to effectively participate in the political decision-making process (Emmenegger et al. 2015). These include professional expertise or intellectual capabilities, which facilitate the understanding of social and political information; communication skills, which can be used in interactions with political candidates; and organizational abilities as well as the strength of personal and political networks. Importantly, every single citizen we consider here is too small to influence politics directly by means of their resources. That is, their resource endowment does not immediately shape political outcomes, e. g, by making a large donation to a political candidate, but the resource endowment determines the individual ability to understand the political process, evaluate manifestos and the accuracy of political debates, and assess politicians' aptitude. This in turn determines individual utility from partaking in the political process and the resulting utility to do so.

By assumption, the advantaged are better endowed, having a resource level of $\bar{r}$, while the disadvantaged have at their disposal a resource level of $\underline{r}<\bar{r}$. We set the resource level of a citizen equal to their political efficacy. The difference in resources implies that citizens are unequal with respect to political efficacy.

In regards to the second feature, two established parties $j \in\{A, B\}$ compete for support from members of both social groups in a multidimensional policy space. The first dimension $p_{j} \in[0,1]$ represents the main policy up for discussion. We here use the example of a redistribution tax which is collected from the better-endowed citizens and is then given to the disadvantaged as a state transfer. Accordingly, the disadvantaged wish for a high level of taxation, whereas this is a financial loss for 
the advantaged. As such, the advantaged favor a low tax rate $p_{j}$, and the disadvantaged favor a high tax rate. ${ }^{1}$ Consequently, a party's tax rate proposal $p_{j}$ provides an advantaged voter with utility $u_{a}\left(p_{j}\right)$ with $\frac{\partial u_{a}}{\partial p_{j}}<0$ and $\frac{\partial^{2} u_{a}}{\partial p_{j}^{2}}>0$. In contrast, utility of the disadvantaged $u_{d}$ increases in the tax rate $p_{j}$, i. e., $\frac{\partial u_{d}}{\partial p_{j}}>0$, and $\frac{\partial^{2} u_{d}}{\partial p_{j}^{2}}<0 .{ }^{2}$ Hence, when deciding on a tax rate proposal $p_{j}$, parties weigh losing support from the advantaged against gaining support from the disadvantaged, or vice versa (Lindbeck and Weibull 1987).

The second dimension of the policy space is the individual party bias $\beta_{i j}$ (Lindbeck and Weibull 1987), which depends on party $j$ 's universal political alignment. Party $j$ can align with a number of political ideologies, such as conservatism, liberalism, social democracy or the like. Apart from that, party $j$ can employ different political styles: It can be a populist or non-populist party, a radical party and so on. Hence, the party bias $\beta_{i j}$ captures individual $i$ 's benefit from their overall attachment to and identification with party $j$ ' ideology and political style. Similar to Lindbeck and Weibull (1987), we define the absolute party bias as a random variable $\theta_{i}=\beta_{i B}-\beta_{i A}$. Consequently, an individual aligns with party $A$ if $\theta_{i}<0$ and with party $B$ if $\theta_{i}>0 . \theta_{i}$ is distributed according to a twice continuously differentiable cumulative distribution function $F_{a}=F_{d}=F$ known to the parties. The associated positive density function is $f$, which is symmetric around 0 (Lindbeck and Weibull 1987). That is, we assume, just for the sake of simplicity, that party biases for $A$ and $B$ are identically distributed in both social groups. All of the following calculations can likewise be performed for congruent densities $f_{g}\left(\theta_{i}\right)=f\left(\theta_{i}+\alpha_{g}\right)$ with $\alpha_{a} \neq \alpha_{d}$ to capture inter-group differences in party biases ${ }^{3}$ (Lindbeck and Weibull 1987).

Combining the two elements, individual $i$ 's additive utility from political support for party $j$ reads

$$
U_{i g}\left(p_{j}\right)=u_{g}\left(p_{j}\right)+\beta_{i j}
$$

By definition, we have utility $U_{i g}>0$ for all values of the tax rate $p_{j}$. In order to decide which party to vote for, individuals compare utilities resulting from the parties' tax rate proposals $p_{A}$ and $p_{B}$ and choose the option which promises the higher utility. That is, we can determine the individual voting probability for party $j$ as

\footnotetext{
${ }^{1}$ Another suitable example is migration policy (Rydgren 2007; Mudde 2013; Coffé et al. 2007; Rodrik 2018), a key feature of recent right-wing populist platforms. In this case, $p_{j}$ can be thought of as the degree to which international migration from less developed countries into the economy under observation is limited. Labor economics argue that immigrants can usually be considered low-skilled workers due to shortages in professional and language skills required to work in the receiving country. While they constitute complements to the better-educated high-income labor suppliers, the low-skilled native population competes for jobs with the immigrants. Therefore, the advantaged can be expected to prefer high levels of immigration, while the opposite is true for the disadvantaged (Card 1990; Georgiadou et al. 2018; Guiso et al. 2018; Rodrik 2018).

${ }^{2}$ In principle, preferences could also be the other way around, depending on the specific policy, without changing the main results as long as the preferences of the two groups are opposing.

${ }^{3}$ In the sense that the disadvantaged lean more towards (left-wing) party $A$ while the advantaged lean more towards (right-wing) party $B$ or vice versa (Lindbeck and Weibull 1987).
} 


$$
v_{g j}\left(p_{j}\right)=\operatorname{Prob}\left[U_{i g}\left(p_{j}\right)>U_{i g}\left(p_{-j}\right)\right]=F\left[u_{g}\left(p_{j}\right)-u_{g}\left(p_{-j}\right)\right]
$$

In order to model the role of political efficacy in the participation decision, we exploit and extend what Lindbeck and Weibull (1987) call the exit case. Here, they allow individuals to abstain from the political process if neither party's platform promises to be sufficiently rewarding to provide support. In this setting, the advantaged, more politically effective citizens receive a relatively larger utility from political involvement. That is because, due to their higher level of resources, they are better at evaluating a party's program, assessing the political aptitude of candidates, and communicating within their networks.

The disadvantaged, however, face a resource shortage of $\epsilon=\bar{r}-\underline{r}>0$. Their political efficacy, and, hence, their utility from political involvement, is reduced by $\epsilon$,

$$
U_{i d}\left(p_{j}\right)=u_{d}\left(p_{j}\right)+\beta_{i j}-\epsilon .
$$

Thus, the probability that a disadvantaged individual supports a party $j$ changes to

$$
v_{d j}\left(p_{j}\right)=F\left[u_{d}\left(p_{j}\right)-u_{d}\left(p_{-j}\right)-\epsilon\right] .
$$

Consequently, if a disadvantaged individual does not receive enough utility from party $j$ 's policy proposal and from general attachment to party $j$ to compensate for the efficacy shortage $\epsilon$, the individual will decide to abstain from politics.

Let us now turn towards the political supply side. Analogous to the baseline setting in Lindbeck and Weibull (1987), the objective of a party $j$ is to maximize its support total ${ }^{4} V_{j}$ which is equal to

$$
V_{j}=n_{a} v_{a j}+n_{d} v_{d j}
$$

over the tax rate $p_{j}$.

The timing of decisions is as follows. First, parties simultaneously propose tax rates $p_{A}, p_{B}$. Then, citizens learn about the proposals and, all at the same time, decide which party to support. Subsequently, parties collect their support and the winner implements the proposed tax rate. ${ }^{5}$ We define a Nash equilibrium (NE) as a combination of proposed tax rates and support decisions that maximizes each player's utility given all other players' strategies. Furthermore, we refer to the optimal tax rate parties propose in our setting as $p^{*^{\prime}}$ and to the optimal tax rate in the baseline textbook case with equally politically effective groups (Lindbeck and Weibull 1987) as $p^{*}$.

Proposition 1 In case of political inequality, i. e., the resource shortage $\epsilon>0$,

\footnotetext{
${ }^{4}$ Even though we start with two parties here and the market entrance of a third party rather suggests that we are in a multiparty system, our considerations are, in principle, applicable to any representation system. This is why we follow the classic theory of voting and Lindbeck and Weibull (1987) in modeling the general case of support-maximizing parties.

${ }^{5}$ We suppose that credible commitment to a tax rate proposal is possible.
} 


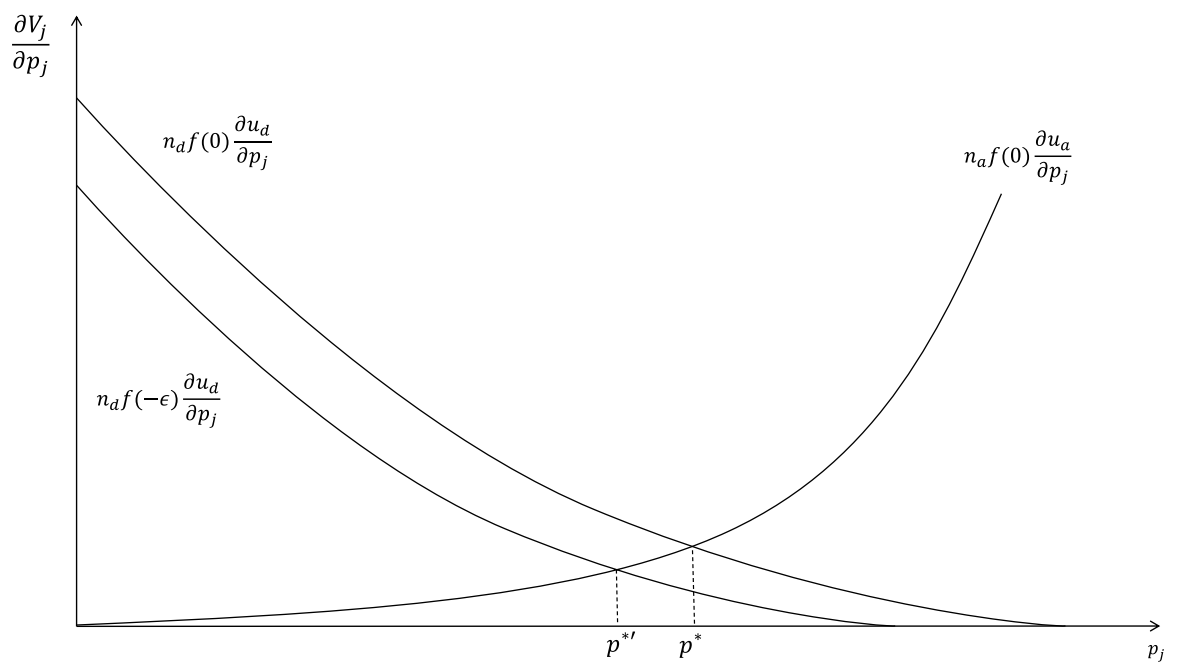

Fig. 1 Equilibrium tax rates with political equality and inequality

a) parties choose subgame-perfect NE tax rates $\left(p_{A}, p_{B}\right)$ so that $p_{A}=p_{B}=p^{*^{\prime}}<p^{*}$ and tax rates are skewed towards the interests of the advantaged.

b) voters choose subgame-perfect $N E$ support levels $\left(v_{a A}, v_{a B}, v_{d A}, v_{d B}\right)$ with $v_{a A}=v_{a B}=0.5>v_{d A}=v_{d B}$. The disadvantaged turn out with a probability lower than 1 and are relatively underrepresented.

Proof See appendix.

Due to their lower political efficacy, the disadvantaged have a lower probability of participating in the political process in the first place. Thus, they constitute a less attractive target group from the established parties' point of view. Compared to the equality case, the marginal benefit from support of the disadvantaged is lower for every tax rate proposal $p_{j}$, as it is weighed down by the lower likelihood of participating (see Fig. 1). As a result, policymakers propose a tax rate which disproportionately benefits the advantaged. The intersection between marginal benefits from support from each group in Fig. 1 shifts left, causing the equilibrium tax rate $p^{*^{\prime}}$ to decrease compared to the equilibrium tax rate with political equality $p^{*}$.

Figure 2 illustrates the resulting support decisions of voters. Advantaged voters have a positive utility from political support for either party. Thus, they have a participation probability of 1 and, because of the equal tax rate proposals $p_{A}=p_{B}=p^{*^{\prime}}$, choose either party with equal probability, according to their ideological bias (see Fig. 2a). Disadvantaged individuals, however, support parties $A$ and $B$ with positive probabilities $v_{d A}, v_{d B}$ with $v_{d A}+v_{d B}<1$. Thus, there is a positive probability $1-v_{d A}-v_{d B}$ that a disadvantaged individual will choose neither party and abstain from the political process. Figure $2 \mathrm{~b}$ illustrates this rationale. Disadvantaged individuals with an absolute party bias $\left|\theta_{i}\right|>\epsilon$ are committed enough to either party $A$ or $B$ to outweigh the low utility from the tax 


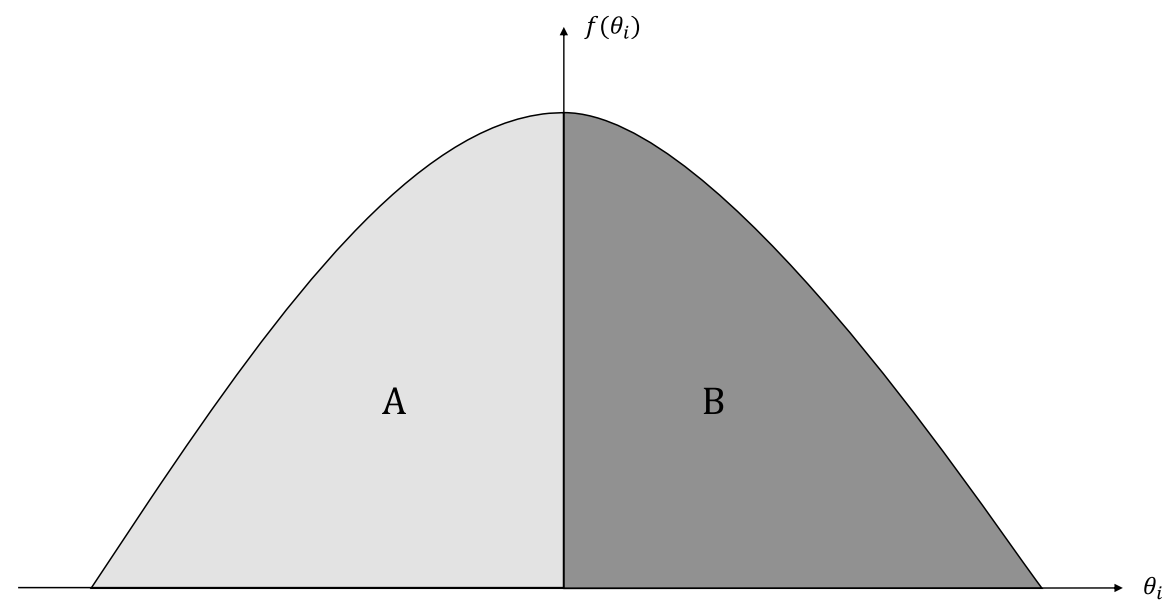

(a) Advantaged voters

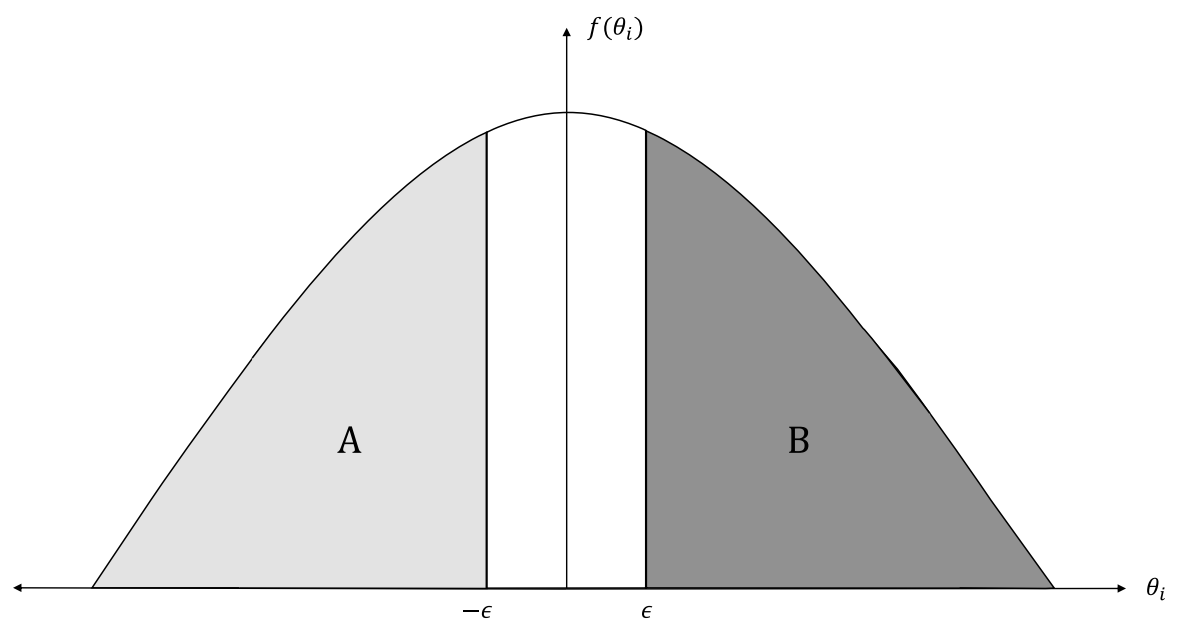

(b) Disadvantaged voters

Fig. 2 Support decisions with political inequality

rate proposal and the political efficacy shortage so that they still support their preferred party (shaded areas in Fig. 2b). Those with a weaker ideological bias, however, do not receive enough utility from supporting a party and decide to abstain (white area in Fig. 2b). Support probabilities $v_{d A}, v_{d B}$ are both decreasing in the resource shortage $\epsilon$ so that a more sizable efficacy shortage causes a disadvantaged individual's participation rate to decline (Emmenegger et al. 2015; Acemoglu et al. 2013; Guiso et al. 2018). 


\subsection{Market entrance of a challenger party}

Although it is optimal for parties $A$ and $B$ to target the advantaged by means of their tax rate proposals, the share of unused support due to abstention may grow substantially, particularly if the resource shortage $\epsilon$ is large. As $\epsilon \rightarrow \infty$, the probability that the disadvantaged abstain approaches 1 . In societies with relatively more disadvantaged voters and a sufficiently large resource shortage $\epsilon$, a majority of voters does not participate in the political process. The high abstention rate can be compared to positive profits on the political market which encourage a new party to enter the political stage and sway the alienated voters (Congleton and Steunenberg 1998).

The challenger party $C$ proposes a tax rate $p_{C} . C$ is a typically populist platform, employing a simplified rhetoric that directly speaks to the common people and reduces the complexity of social problems to an unrealistic but easily understandable take-away message (Mudde 2004, 2013; Guiso et al. 2018). Members of party $C$ have a more direct connection to the electorate and are more easily approachable, even by disadvantaged voters. Therefore, members of group $d$ generally feel attached to party $C$, as $C$ 's populist strategy partly outweighs their political efficacy shortage. Thus, the respective party bias is positive for all disadvantaged individuals, $\beta_{i C}>0$. The negative of the party bias $\left(-\beta_{i C}\right)^{6}$ is drawn from a twice continuously differentiable c.d.f $\Phi$ with positive density $\phi$. By contrast, advantaged voters dislike the simplified style of party $C$ and do not identify much with the party. To keep the results particularly simple, we assume that all advantaged voters have a bias of 0 for party $C, \beta_{i C}=0$.

Let us first consider the somewhat more straightforward rationale of advantaged voters in this extended case. They now have a third political option and will support party $C$ if the benefit from $C$ 's tax rate proposal exceeds the benefit to be gained from supporting either party $A$ or $B$. Let $u_{a}\left(p_{C}\right)>0$ be the utility from $C$ 's tax rate proposal $p_{C}$ for an advantaged individual. Their new likelihood of supporting party $A$ or $B$ reads

$$
v_{a A}=F\left[\Delta-u_{a}\left(p_{C}\right)\right]=1-F\left[u_{a}\left(p_{C}\right)-\Delta\right]=v_{a B} .
$$

In a two-party scenario, parties $A$ and $B$ only had to provide sufficient utility to advantaged members to cross a utility threshold of 0 , which is always the case. Now, however, the minimum utility that the established parties have to provide increases to the level of utility promised by party $C$. Consequently, only advantaged individuals with an absolute party bias of $\theta_{i}<-u_{a}\left(p_{C}\right)$ will be willing to support party $A$. Likewise, individuals with $\theta_{i}>u_{a}\left(p_{C}\right)$ will side with party $B$. Those, however, with an absolute party bias $\left|\theta_{i}\right|<u_{a}\left(p_{C}\right)$ will switch to the challenger party $C$ (cf. Fig. 3a). Again, there is no abstention among the advantaged.

Support decisions among the disadvantaged can be determined in a similar way. All disadvantaged individuals have four options. They can decide to support one of the established parties, to support the populist challenger or not to

\footnotetext{
${ }^{6}$ We here define the c.d.f. of $-\beta_{i C}$ instead of $\beta_{i C}$ to obtain slightly simpler results later.
} 


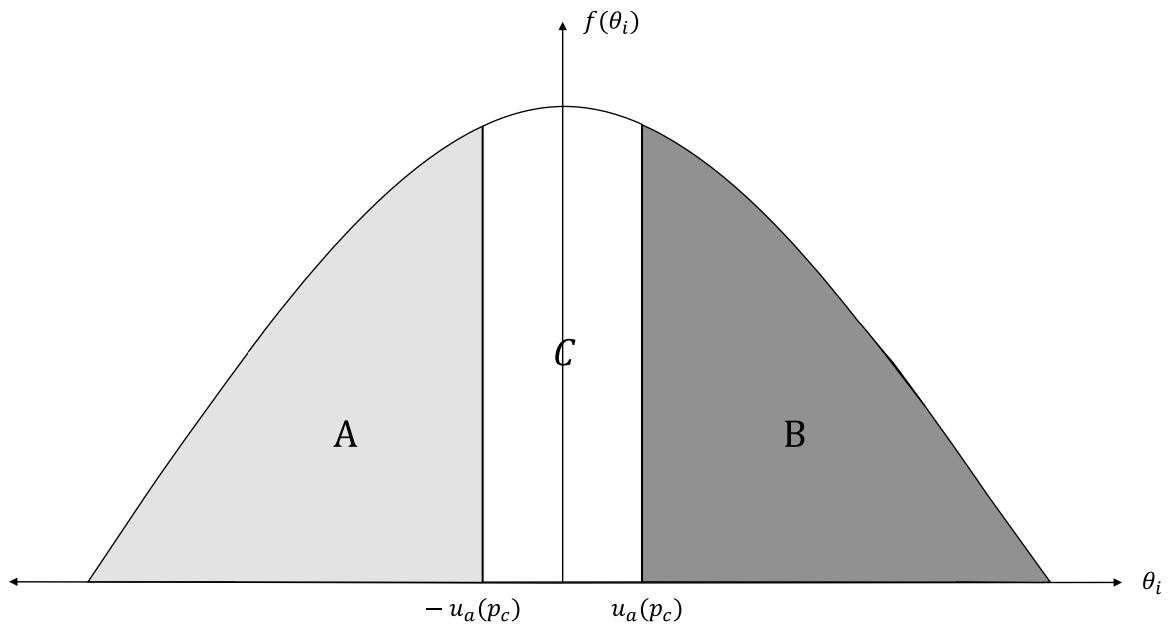

(a) Advantaged voters

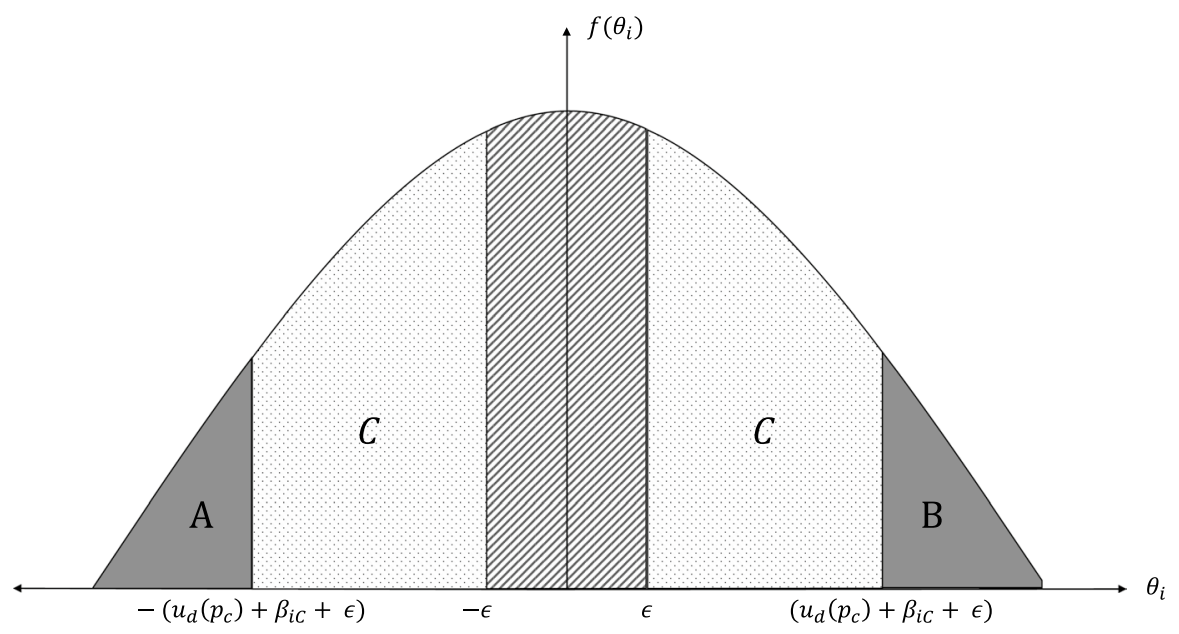

(b) Disadvantaged voters

Fig. 3 Voting decisions with a challenger party

participate at all. Out of these options, a disadvantaged individual again chooses the option which promises the highest utility.

Figure $3 \mathrm{~b}$ illustrates a disadvantaged individual's rationale. Supporting an established party only pays off for individuals for whom the net utility from doing so is positive and at the same time larger than the utility from supporting party $C$, i. e., $\Delta-\theta_{i}-\epsilon>u_{d}\left(p_{C}\right)+\beta_{i C}>0$. Consequently, all individuals with an absolute 
party bias $\theta_{i}<-\left(u_{d}\left(p_{C}\right)+\beta_{i C}+\epsilon\right)$ support party $A$, while all individuals with $\theta_{i}>u_{d}\left(p_{C}\right)+\beta_{i C}+\epsilon$ support party $B$ (shaded areas in Fig. $3 \mathrm{~b}$ ).

If the absolute party bias $\left|\theta_{i}\right| \in\left(\epsilon, u_{d}\left(p_{C}\right)+\beta_{i C}+\epsilon\right)$, utility from supporting party $A$ or $B$ is still positive but is lower than utility from supporting party $C$. This implies that party $C$ must be the preferred option for the respective disadvantaged citizens and that party $C$ here succeeds in enticing voters from the established parties (dotted area in Fig. 3b).

In addition, party $C$ can also win voters from those who would otherwise have abstained. For all disadvantaged individuals with $\left|\theta_{i}\right|<\epsilon$, utility from supporting an established party is lower than 0 . These voters are weakly committed to either established party but they only switch to challenger party $C$ if utility from doing so is greater than their resource shortage, $u_{d}\left(p_{C}\right)+\beta_{i C}>\epsilon$. Hence, party $C$ sways abstainers with probability $\operatorname{Pr}\left[u_{d}\left(p_{C}\right)+\beta_{i C}>\epsilon\right]=\Phi\left[u_{d}\left(p_{C}\right)-\epsilon\right]$ (striped area in Fig. 3b).

Anticipating this voter behavior, parties propose optimal tax rates $p_{A, B}^{*^{\prime \prime}}$ and $p_{C}^{*^{\prime \prime}}$, respectively, for which the following holds:

Proposition 2 With political inequality, i. e., the resource shortage $\epsilon>0$,

a) the challenger party $C$ proposes a subgame-perfect $N E$ tax rate $p_{C}^{* \prime \prime}>p^{*}$.

$b)$ the established parties $A$ and $B$ propose a subgame-perfect NE tax rate $p_{A, B}^{* \prime \prime}<p_{C}^{* \prime \prime}$

c) After reaching a maximum, party C's tax rate proposal $p_{C}^{*^{\prime \prime}}$ decreases in the resource shortage $\epsilon$.

d) Party A and B's tax rate proposal $p_{A, B}^{* \prime \prime}$ decreases in the resource shortage $\epsilon$.

Proof See appendix.

The equilibrium strategy of party $C$ always implies a higher tax rate compared to the opponents, which more strongly appeals to the disadvantaged. ${ }^{7}$ On this basis, party $C$ targets two types of swing voters in this group: first, those who are indifferent between voting for an established party and voting for party $C$ and, second, those who are indifferent between voting for $C$ and not participating at all. While parties $A$ and $B$ cannot win the abstainers and, thus, have no incentive to occupy a position complying with their interests, party $C$ is supported by this group with positive probability $\Phi\left[u_{d}\left(p_{C}\right)-\epsilon\right]$. Therefore, party $C$ proposes a tax rate which is more beneficial for these voters.

The larger the resource shortage of the disadvantaged, the lower the equilibrium tax rate any party will propose. While the challenger party always leans more towards the disadvantaged than the established parties do, its tax rate proposal

\footnotetext{
7 This result is comparable to a result proposed by Congleton and Steunenberg (1998), implying that political challengers increase their chances of electoral success by proposing a policy that is different from the competitors' policy proposals.
} 


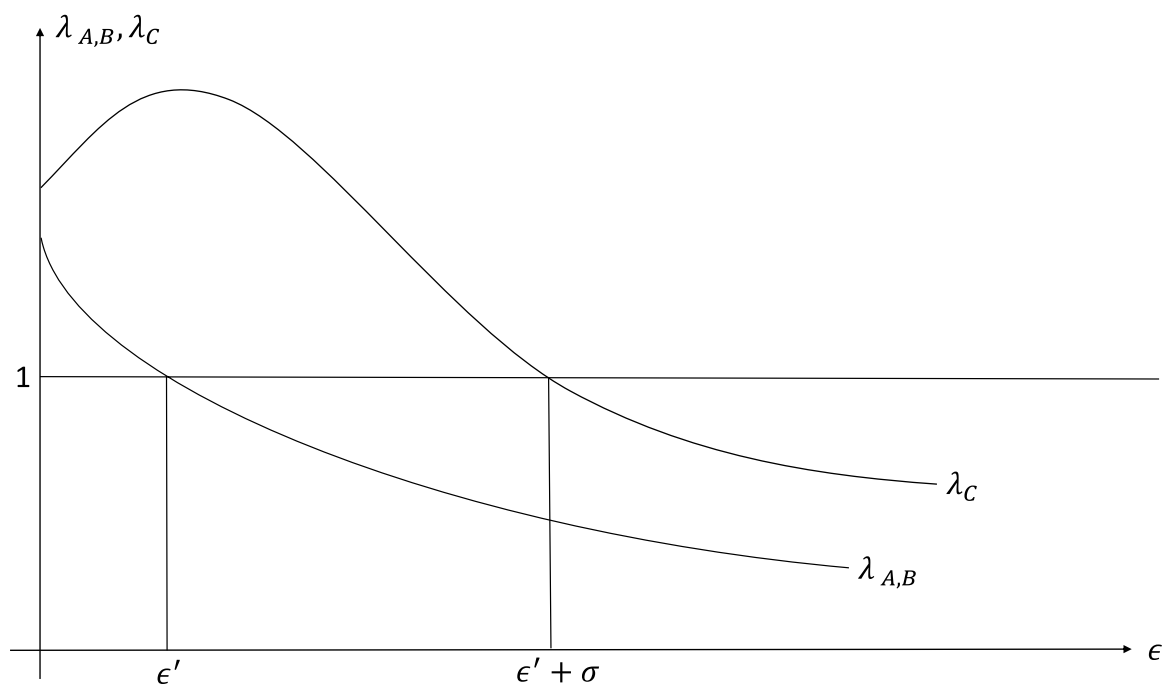

Fig. 4 Party strategies for values of $\epsilon$

nevertheless declines for large values of the resource shortage $\epsilon$. A greater efficacy shortage among the disadvantaged lowers the likelihood that they will vote, which is harmful to either party's support count.

Furthermore, although $C$ 's equilibrium tax rate proposal $p_{C}^{*^{\prime \prime}}$ is larger than party $A$ and $B$ 's proposals $p_{A, B}^{* \prime \prime}$ in any case, this does not necessarily exclude the possibility that $C$ will still disproportionately benefit the advantaged. The optimization process of parties with respect to the tax rate $p_{j}$ implies balancing the marginal utilities from this proposal for both advantaged and disadvantaged citizens (see Eqs. (A.13) and (A.17) in the appendix). Denote by $\lambda_{j}$ the weight that party $j$ attributes to the marginal policy utility of the disadvantaged. If this weight is larger than 1 , the disadvantaged are the main target group, resulting in a tax rate respectively biased. If it is smaller than 1 , the advantaged are the main target group.

Proposition 3 With political inequality, i. e., the resource shortage $\epsilon>0$, there exists an interval $\left(\epsilon^{\prime}, \epsilon^{\prime}+\sigma\right)$ so that

a) $\lambda_{C}>\lambda_{A, B}>1$ if $\epsilon^{\prime}>\epsilon$.

b) $\lambda_{C}>1>\lambda_{A, B}$ if $\epsilon^{\prime}+\sigma>\epsilon>\epsilon^{\prime}$.

c) $1>\lambda_{C}>\lambda_{A, B}$ if $\epsilon>\epsilon^{\prime}$.

Figure 4 illustrates these different combinations of the weight $\lambda_{j}$ for values of the resource shortage $\epsilon$. In relatively equal societies, i. e., when $\epsilon$ is low, there are small differences in participation probabilities. The disadvantaged thus receive a disproportionately high weight in parties' objective functions because it pays off for parties to choose a tax rate which mobilizes these only slightly disadvantaged voters. 
However, as the resource shortage $\epsilon$ increases, political participation among the disadvantaged decreases. Mobilizing them involves strong increases in tax rates $p_{j}$ and, therefore, has high costs in terms of advantaged support. For resource shortages of $\epsilon>\epsilon^{\prime}$, it is too costly for parties $A$ and $B$ to try to win disadvantaged voters by means of higher tax rate proposals because they would lose too much advantaged support, see Fig. 4. Yet as $\lambda_{C}>\lambda_{A, B}$, there must be an interval $\left(\epsilon^{\prime}, \epsilon^{\prime}+\sigma\right)$ with $\sigma>0$ for which $\lambda_{C}>1>\lambda_{A, B}$. Consequently, in societies with medium levels of political inequality, party strategies diverge. However, once the resource shortage $\epsilon$ exceeds the critical level of $\epsilon+\sigma$, it is $1>\lambda_{C}>\lambda_{A, B}$, meaning that all parties will cater to the interests of the advantaged, yet party $C$ does so to a lesser extent.

Having discussed the implications for the policy level, we can now revisit support decisions of voters.

Proposition 4 With political inequality, i. e., the resource shortage $\epsilon>0$,

a) advantaged voters choose subgame-perfect $N E$ support levels $\left(p_{a A}, p_{a B}, p_{a C}\right)$ with $p_{a A}=p_{a B}$.

b) disadvantaged voters choose subgame-perfect $N E$ support levels $\left(p_{d A}, p_{d B}, p_{d C}\right)$ with $p_{d A}=p_{d B}<p_{d C}$.

Proof See appendix.

Because party $C$ 's tax rate proposal is closer to the preferred taxation level of the disadvantaged, they are more likely to support $C$ compared to the established parties.

Since the main objective of the model at hand is to theoretically link real-world observations of political inequality, participation incentives and populist challengers, we finally discuss to which countries and political systems our approach may refer. In principle, our considerations can be applied to any party system. In some cases, e. g., the United States, populism appeared as one candidate in a two-party system (Norris and Inglehart 2019) while the party the candidate represented was not, as a whole, a populist one. In the same vein, the challenger does not have to be separate party but could be a wing of an established party which secedes and competes as a political alternative. The United Kingdom, a traditional two-party system, observed the emergence of a populist challenger. This is quite close to our model setting (Hobolt 2016; Norris and Inglehart 2019). Over the last years, multiparty systems, e. g., in Europe, witnessed the emergence of one or even several populist parties (Algan et al. 2017; Guriev and Papaioannou 2021; Norris and Inglehart 2019; Rodrik 2018) that challenged big people's parties. Thus, while some of the roles of single agents in our model need to be reinterpreted, the qualitative results we obtain remain applicable to a number of different settings.

A final remark considers the ability of parties to win back the abstainers. In our setting, the challenger succeeds in doing so due to its populist platform, which provides a special benefit to alienated citizens. However, in principle, any party may 
be able to change its overall platform towards one that particularly appeals to the disadvantaged. While we implicitly made the realistic assumption that a party's general political alignment and style is fixed when it is founded and enters the political stage, this alignment may change over time, at least in the long run. Thus, after some time, an established party may want to revise its platform. The remaining question would be whether the party would turn populist or would reach a greater identification with the abstaining by means of other stylistic and ideological elements.

\section{Conclusion}

A vast body of social science literature has tried to explain the recent success of populist parties in Western democracies. Placing special emphasis on the role of political inequality, we extend the probabilistic voting model in order to illustrate how shortages in political efficacy fuel abstention and open a gateway for populist parties to win an alienated electorate. Two groups of citizens, the advantaged and the disadvantaged, favor conflicting policy levels. The utility citizens receive from political participation depends on a policy realization as well as on their general party attachment. The disadvantaged are endowed with a lower level of politically valuable resources, which impedes political involvement. Consequently, political participation is lower for the disadvantaged than for the advantaged.

Two established parties seek to maximize their respective support from both social groups. In equilibrium, they uniformly converge to a tax rate proposal which is biased towards the advantaged in order to secure votes from those with a higher probability of participating. This stimulates support from the advantaged while further discouraging the disadvantaged from participating. A newly emerging party can realize gains by entering the political market with a combination of a simple, populist style and a tax rate proposal particularly beneficial to the disadvantaged. Thereby, the challenger re-stimulates political participation among the disadvantaged and receives hitherto foregone votes. However, with high levels of political inequality, participation rates among the disadvantaged are so low that they do not constitute an attractive target group for any party.

Our results offer some practically relevant implications for political agents. The emergence of a populist challenger here is rooted in the uniform bias of established parties towards a privileged electorate. Although this strategy is efficient, it leads to votes being systematically waived. A clear focus on distinct target groups could solve this dilemma, as it enables established parties to realize higher total support and, at the same time, curb incentives for competitors to enter the political market. Furthermore, an accessible and voter-oriented communication gives disadvantaged citizens the chance to deal with political issues and increase identification. Importantly, disadvantaged citizens would not have to turn towards populist parties, which not only offer more accessible platforms but are also associated with authoritarian, anti-democratic values and the spread of false information (Mudde 2004, 2013; Guiso et al. 2018, 2020). Finally, we highlight the ineffectiveness of abstention as a measure of protest. Withdrawing from 
public decision-making is the economically optimal choice but it does not bring about the intended change in political positions of the established parties.

Our considerations leave open several avenues for further research. Foremost, we take the level of political inequality as given. A potentially interesting extension could be to endogenously determine political inequality in the political process. Here, the dynamic interaction of inequality and policy outcomes over time may provide meaningful insights into the long-term evolution of the political system. Furthermore, our model outcomes imply an empirically testable hypothesis, namely that the relation between political inequality and polarization should be inversely u-shaped. Respective empirical evidence may contribute to a reassessment of the role of inequality with respect to political regime transformation.

\section{Appendix: Proofs}

Proof to Proposition 1 For comparison purposes, we first present the original baseline case as in Lindbeck and Weibull (1987) without a political efficacy measure. As outlined in Sect. 2.1, individual $i$ will support party $A$ if the utility from doing so is greater than the utility from supporting party $B, U_{i g}\left(p_{A}\right)>U_{i g}\left(p_{B}\right)$. The resulting support probability $v_{g A}$ equals

$$
\begin{aligned}
v_{g A} & =\operatorname{Pr}\left[U_{i g}\left(p_{A}\right)>U_{i g}\left(p_{B}\right)\right]=\operatorname{Pr}\left[U_{i g}\left(p_{A}\right)-U_{i g}\left(p_{B}\right)>0\right] \\
& =\operatorname{Pr}\left[u_{g}\left(p_{A}\right)-u_{g}\left(p_{B}\right)>\theta_{i}\right]=F\left[u_{g}\left(p_{A}\right)-u_{g}\left(p_{B}\right)\right] .
\end{aligned}
$$

Likewise, an individual will support party $B$ if $U_{i g}\left(p_{A}\right)<U_{i g}\left(p_{B}\right)$, corresponding to a support probability $v_{g B}$ with

$$
\begin{aligned}
v_{g B} & =\operatorname{Pr}\left[U_{i g}\left(p_{A}\right)<U_{i g}\left(p_{B}\right)\right]=\operatorname{Pr}\left[U_{i g}\left(p_{A}\right)-U_{i g}\left(p_{B}\right)<0\right] \\
& =\operatorname{Pr}\left[u_{g}\left(p_{B}\right)-u_{g}\left(p_{A}\right)>\theta_{i}\right]=F\left[u_{g}\left(p_{B}\right)-u_{g}\left(p_{A}\right)\right] .
\end{aligned}
$$

Party $j$ maximizes its objective function

$$
V_{j}=n_{a} v_{a j}+n_{d} v_{d j}
$$

Inserting the voting probabilities as in Eq. (A.1) and (A.2) and taking the first derivative of Eq. (A.3) w.r.t. the tax rate proposal $p_{j}$, the first-order condition for a maximum is

$$
n_{a} f(\Delta) \frac{\partial u_{a}}{\partial p_{j}}=n_{d} f(\Delta) \frac{\partial u_{d}}{\partial p_{j}}
$$

with density $f(\cdot)$ being evaluated at the utility differential $\Delta=u_{i}\left(p_{j}\right)-u_{i}\left(p_{-j}\right)$.

Both parties face the same maximization problem so that in equilibrium, they propose the same tax rate $p_{A}=p_{B}=p^{*}$. Since $u_{g}\left(p_{A}\right)=u_{g}\left(p_{B}\right)=u_{g}\left(p^{*}\right)$, the utility differential $\Delta$ equals 0 and rearranging Eq. (A.4) yields 


$$
\frac{n_{a} \frac{\partial u_{a}}{\partial p_{j}}}{n_{d} \frac{\partial u_{d}}{\partial p_{j}}}=\frac{f(0)}{f(0)}=1
$$

When all citizens are equally politically effective and $p_{A}=p_{B}=p^{*}$, the decisive dimension is the party bias $\theta_{i}$. Parties balance the marginal utilities of the swing voters in each group who are individuals with a party bias $\theta_{i}=0$ (Lindbeck and Weibull 1987).

Since we are concerned with the feedback effect of the parties' proposals on support probabilities, we take a look at the resulting support probabilities $v_{g A}, v_{g B}$ in Eqs. (A.1) and (A.2). Given that the utility differential $\Delta=0$, we find

$$
v_{g A}=F[0]=\frac{1}{2}=v_{g B} .
$$

All voters base their choice solely on their individual party bias. All voters with an absolute bias $\theta_{i}<0$ support party $A$, while all voters with $\theta_{i}>0$ support party $B$. Since $v_{g A}=1-v_{g B}$, support probabilities sum up to 1 and there is no abstention (Lindbeck and Weibull 1987).

Now, we consider the case where the resource shortage $\epsilon>0$, i. e., the disadvantaged are relatively less politically effective. The support probability for party $j$ among the disadvantaged changes to

$$
v_{d j}\left(p_{j}\right)=F\left[u_{d}\left(p_{j}\right)-u_{d}\left(p_{-j}\right)-\epsilon\right] .
$$

Both parties $A$ and $B$ again face the same maximization problem as in Eq. (A.3) with a support probability $v_{d j}$ as in Eq. (A.7). Therefore, we still have equilibrium tax rate proposals $p_{A}=p_{B}=p^{*^{\prime}}$ and a utility differential $\Delta=0$. The first-order condition now denotes

$$
n_{a} f(0) \frac{\partial u_{a}}{\partial p_{j}}=n_{d} f(-\epsilon) \frac{\partial u_{d}}{\partial p_{j}} .
$$

so that in equilibrium, we have a tax rate proposal $p^{*^{\prime}}$ which must satisfy

$$
\frac{n_{a} \frac{\partial u_{a}}{\partial p^{*^{\prime}}}}{n_{d} \frac{\partial u_{d}}{\partial p^{*^{\prime}}}}=\frac{f(\epsilon)}{f(0)} .
$$

As the density function $f(\cdot)$ is centered around $0, f(\epsilon)<f(0)$ for any value of the resource shortage $\epsilon>0$. Therefore, the right-hand side of Eq. (A.9) is smaller than the right-hand side of Eq. (A.5) in the baseline setting. For Eq. (A.9) to be satisfied, it is necessary for the left-hand side to decrease as well. Since utility of advantaged voters $u_{a}$ is decreasing in the tax rate $p_{j}$ and utility of disadvantaged voters $u_{d}$ is increasing in the tax rate $p_{j}, p_{j}$ must be smaller compared to the case with politically equally effective voters, i. e., $p^{*^{\prime}}<p^{*}$.

Support decisions of the advantaged remain unchanged 


$$
v_{a A}=F[0]=\frac{1}{2}=v_{a B},
$$

whereas support of the disadvantaged now equals

$$
v_{d A}=F[-\epsilon]=1-F[\epsilon]=v_{d B}<\frac{1}{2} .
$$

Since $v_{d A}+v_{d B}<1$, there is a positive abstention probability $1-v_{d A}-v_{d B}$ among the disadvantaged.

Proof to Proposition 2 We consider the case where party $C$ is a populist challenger. That is, we have a party bias $\beta_{i C}=0$ for all advantaged individuals $i \in\{a\}$ and a party bias $\beta_{i C}>0$ for all disadvantaged individuals $i \in\{d\}$. Then, the challenger party $C$ maximizes its objective function

$$
V_{C}=n_{a}\left[1-2 F\left[u_{a}\left(p_{C}\right)-\Delta\right]\right]+n_{d}\left[1-2 F\left[u_{d}\left(p_{C}\right)+\beta_{i C}-\Delta+\epsilon\right]+(F[\epsilon]-F[-\epsilon]) \Phi\left[u_{C}\left(p_{C}\right)-\epsilon\right]\right]
$$

w.r.t. the tax rate proposal $p_{C}$.

Based on Eq. (A.12), party $C$ 's optimal tax rate $p_{C}^{* \prime \prime}$ must satisfy

$$
\frac{n_{a} \frac{\partial u_{a}}{\partial p_{C}^{* \prime \prime}}}{n_{d} \frac{\partial u_{d}}{\partial p_{C}^{* \prime \prime}}}=\frac{f\left(u_{d}\left(p_{C}\right)+\beta_{i C}+\epsilon\right)+(F[\epsilon]-F[-\epsilon]) \phi\left(u_{d}\left(p_{C}\right)-\epsilon\right)}{f\left(u_{a}\left(p_{C}\right)\right)}=\lambda_{C} .
$$

From Eq. (A.13), it follows that

$$
\frac{\partial \lambda_{C}}{\partial \epsilon}=\frac{f^{\prime}\left(u_{d}\left(p_{C}\right)+\beta_{i C}+\epsilon\right)+2 f(\epsilon) \phi\left(u_{d}\left(p_{C}\right)-\epsilon\right)+(F[\epsilon]-F[-\epsilon]) \phi^{\prime}\left(u_{d}\left(p_{C}\right)-\epsilon\right)}{f\left(u_{a}\left(p_{C}\right)\right)} .
$$

While $f^{\prime}\left(u_{d}\left(p_{C}\right)+\beta_{i C}+\epsilon\right)$ is always smaller than 0 , $2 f(\epsilon) \phi\left(u_{d}\left(p_{C}\right)-\epsilon\right)+(F[\epsilon]-F[-\epsilon]) \phi^{\prime}\left(u_{d}\left(p_{C}\right)-\epsilon\right)$ can both be larger or smaller than 0 , depending on the exact parameter values, meaning that the weight assigned to the marginal utility of disadvantaged voters $\lambda_{C}$ first increases, then decreases in the resource shortage $\epsilon$.

The new objective function for parties $A$ and $B$ is

$$
V_{A, B}=n_{a} F\left[\Delta-u_{a}\left(p_{C}\right)\right]+n_{d} F\left[\Delta-\epsilon-u_{d}\left(p_{C}\right)-\beta_{i C}\right] \quad \rightarrow \max _{p_{A, B}} .
$$

Parties $A$ and $B$ have identical maximization problems in Eq. (A.15) so that they will choose the same policy strategy in equilibrium. Maximizing their support w.r.t. the tax rate $p_{j}$ yields the first-order condition

$$
n_{a} f\left(u_{a}\left(p_{C}\right)\right) \frac{\partial u_{a}}{\partial p_{j}}=n_{d} f\left(u_{d}\left(p_{C}\right)+\beta_{i C}+\epsilon\right) \frac{\partial u_{d}}{\partial p_{j}} .
$$

and hence an optimal tax rate proposal $p_{A, B}^{*^{\prime \prime}}$ which satisfies 


$$
\frac{n_{a} \frac{\partial u_{a}}{\partial p_{A, B}^{* \prime \prime}}}{n_{d} \frac{\partial u_{d}}{\partial p_{A, B}^{* \prime \prime}}}=\frac{f\left(u_{d}\left(p_{C}\right)+\beta_{i C}+\epsilon\right)}{f\left(u_{a}\left(p_{C}\right)\right)}=\lambda_{A, B}<\lambda_{C},
$$

From Eq. (A.17), it follows that

$$
\frac{\partial \lambda_{A, B}}{\partial \epsilon}=\frac{f^{\prime}\left(u_{d}\left(p_{C}\right)+\beta_{i C}+\epsilon\right)}{f\left(u_{a}\left(p_{C}\right)\right)}<0
$$

Proof to Proposition 4 Due to the fact that parties $A$ and $B$ follow the same policy strategy in equilibrium, all voters support one of the two established parties with equal probability, $v_{a A}=v_{a B}$ and likewise $v_{d A}=v_{d B}$. As outlined above, the probability of an advantaged individual supporting either $A$ or $B$ is

$$
v_{a A}=F\left[-u_{a}\left(p_{C}\right)\right]=1-F\left[u_{a}\left(p_{C}\right)\right]=v_{a B} .
$$

Consequently, $v_{a C}=1-v_{a A}-v_{a B}=2 F\left[u_{a}\left(p_{C}\right)\right]-1$.

Support for the three parties among the disadvantaged now equals

$$
\begin{aligned}
v_{d A} & =F\left[-\left(u_{d}\left(p_{C}\right)+\beta_{i C}+\epsilon\right)\right]=1-F\left[u_{d}\left(p_{C}\right)+\beta_{i C}+\epsilon\right]=v_{d B} \\
& <1-2 F\left[u_{d}\left(p_{C}\right)+\beta_{i C}+\epsilon\right]+(F[\epsilon]-F[-\epsilon]) \Phi\left[u_{d}\left(p_{C}\right)-\epsilon\right]=v_{d C} .
\end{aligned}
$$

Moreover, there is a positive probability $(F[\epsilon]-F[-\epsilon])\left(1-\Phi\left[u_{d}\left(p_{C}\right)-\epsilon\right]\right)$ that voting for neither party pays off for a disadvantaged individual and that the respective individual will abstain from political decision-making.

Because of their identical policy strategies, parties $A$ and $B$ equally share their expected support, leaving each with a total of

$$
V_{A}=0.5\left[n_{a} F\left[u_{a}\left(p_{C}\right)\right]+n_{d} F\left[u_{d}\left(p_{C}\right)+\beta_{i C}+\epsilon\right]\right]=V_{B} .
$$

Party $C$ 's expected total support is

$$
V_{C}=n_{a}\left[1-2 F\left[u_{a}\left(p_{C}\right)\right]\right]+n_{d}\left[1-2 F\left[u_{d}\left(p_{C}\right)+\beta_{i C}+\epsilon\right]+(F[\epsilon]-F[-\epsilon]) \Phi\left[u_{d}\left(p_{C}\right)-\epsilon\right]\right] .
$$

Funding Open Access funding enabled and organized by Projekt DEAL.

Open Access This article is licensed under a Creative Commons Attribution 4.0 International License, which permits use, sharing, adaptation, distribution and reproduction in any medium or format, as long as you give appropriate credit to the original author(s) and the source, provide a link to the Creative Commons licence, and indicate if changes were made. The images or other third party material in this article are included in the article's Creative Commons licence, unless indicated otherwise in a credit line to the material. If material is not included in the article's Creative Commons licence and your intended use is not permitted by statutory regulation or exceeds the permitted use, you will need to obtain permission directly from the copyright holder. To view a copy of this licence, visit http://creativecommons.org/ licenses/by/4.0/. 


\section{References}

Acemoglu, D., Egorov, G., \& Sonin, K. (2013). A political theory of populism. Quarterly Journal of Economics, 128, 771-805. https://doi.org/10.1093/qje/qjs077.

Acemoglu, D., \& Robinson, J. A. (2008). Persistence of power, elites and institutions. American Economic Review, 98(1), 267-293. https://doi.org/10.1257/aer.98.1.267.

Algan, Y., Guriev, S., Papaioannou, E., \& Passari, E. (2017). The European trust crisis and the rise of populism. Brookings Papers on Economic Activity, 2017(2), 309-400. https://doi.org/10.1353/eca. 2017.0015.

Bonomi, G., Gennaioli, N., \& Tabellini, G. (2021). Identity, Beliefs, and Political Conflict. Quarterly Journal of Economics, 136(4), 2371-2411. https://doi.org/10.1093/qje/qjab034.

Bouvet, F., \& King, S. (2016). Income inequality and election outcomes in OECD countries: New evidence following the Great Recession of 2008-2009. Electoral Studies, 41, 70-79. https://doi.org/10. 1016/j.electstud.2015.11.006.

Brady, H. E., Verba, S., \& Schlozman, K. L. (1995). Beyond SES: A resource model of political participation. American Political Science Review, 89(2), 271-294. https://doi.org/10.2307/2082425.

Burgoon, B., van Noort, S., Rooduijn, M., \& Underhill, G. (2018). Positional deprivation and support for radical right and radical left parties. Economic Policy, 34(97), 49-93. https://doi.org/10.1093/epolic/ eiy017.

Card, D. (1990). The impact of the mariel boatlift on the miami labor market. Industrial and Labor Relations Review, 43(2), 245. https://doi.org/10.2307/2523702.

Coffé, H., Heyndels, B., \& Vermeir, J. (2007). Fertile grounds for extreme right-wing parties: Explaining the Vlaams Blok's electoral success. Electoral Studies, 26, 142-155. https://doi.org/10.1016/j.elect stud.2006.01.005.

Congleton, R. D., \& Steunenberg, B. (1998). Voter discernment and candidate entry in pluralitarian elections. Public Choice, 95(3-4), 287-306. https://doi.org/10.1023/a:1004988909378.

Drazen, A., Limao, N., \& Stratmann, T. (2007). Political contribution caps and lobby formation: Theory and evidence. Journal of Public Economics, 91, 723-754. https://doi.org/10.1016/j.jpubeco.2006. 10.005 .

Durante, R., Pinotti, P., \& Tesei, A. (2019). The political legacy of entertainment TV. American Economic Review, 109(7), 2497-2530. https://doi.org/10.1257/aer.20150958.

Eichhorst, W., \& Marx, P. (2011). Reforming German labour market institutions: A dual path to flexibility. Journal of European Social Policy, 21(1), 73-87. https://doi.org/10.1177/0958928710385731.

Emmenegger, P., Marx, P., \& Schraff, D. (2015). Labour market disadvantage, political orientations and voting: How adverse labour market experiences translate into electoral behavior. Socio-Economic Review, 13(2), 189-213. https://doi.org/10.1093/ser/mwv003.

Gallego, A. (2010). Understanding unequal turnout: Education and voting in comparative perspective. Electoral Studies, 29, 239-248. https://doi.org/10.1016/j.electstud.2009.11.002.

Georgiadou, V., Rori, L., \& Roumanias, C. (2018). Mapping the far-right in the 21st century: A mesolevel analysis. Electoral Studies, 54, 103-115. https://doi.org/10.1016/j.electstud.2018.05.004.

Gerber, A. S., Huber, G. A., Doherty, D., \& Dowling, C. M. (2011). Citizens' policy confidence and electoral punishment: A neglected dimension of electoral accountability. Journal of Politics, 73(4), 1206-1224. https://doi.org/10.1017/s0022381611000892.

Gest, J., Reny, T., \& Mayer, J. (2017). Roots of the radical right: Nostalgic deprivation in the United States and Britain. Comparative Political Studies, 51(13), 1694-1719. https://doi.org/10.1177/ 0010414017720705.

Gethin, A., Martinez-Toledano, C., \& Piketty, T. (2021). Brahmin left versus merchant right: Changing political cleavages in 21 Western Democracies, 1948-2020. Quarterly Journal of Economics, forthcoming. https://doi.org/10.1093/qje/qjab036.

Geys, B. (2006). Explaining voter turnout: A review of aggregate-level research. Electoral Studies, 25, 637-663. https://doi.org/10.1016/j.electstud.2005.09.002.

Gilens, M., \& Page, B. I. (2014). Testing theories of American Politics: Elites, interest groups, and average citizens. Perspectives on Politics, 12(3), 564-581. https://doi.org/10.1017/S1537592714001595.

Golder, M. (2003). Explaning variation in the success of extreme right parties in Western Europe. Comparative Political Studies, 36(4), 432-466. https://doi.org/10.1177/0010414003251176.

Goodin, R., \& Dryzek, J. (1980). Rational participation: The politics of relative power. British Journal of Political Science, 10(3), 273-292. https://doi.org/10.1017/S0007123400002209. 
Grossman, G., \& Helpman, E. (1994). Protection for sale. American Economic Review, 84(4), 833-850. https://doi.org/10.1007/978-3-540-79247-5_7.

Grossman, G., \& Helpman, E. (2021). Identity politics and trade policy. Review of Economic Studies, 88(3), 1101-1126. https://doi.org/10.1093/restud/rdaa031.

Guiso, L., Herrero, H., Morelli, M., \& Sonno, T. (2018). Populism: Demand and supply. Working Paper. https://doi.org/10.1111/spsr.12332

Guiso, L., Herrero, H., Morelli, M., \& Sonno, T. (2020). Economic insecurity and the demand of populism in Europe. Available at: https://www.heliosherrera.com/ populism.pdf.

Guriev, S., \& Papaioannou, E. (2021). The political economy of Populism. Journal of Economic Literature, forthcoming.

Han, K. J. (2016). Income inequality and voting for radical right-wing parties. Electoral Studies, 42, 54-64. https://doi.org/10.1016/j.electstud.2016.02.001.

Hirshman, A. O. (1970). Exit, voice, and loyalty: Responses to declines in firms, organizations, and states. Cambridge: Harvard University Press.

Hobolt, S. B. (2016). The Brexit vote: A divided nation, a divided continent. Journal of European Public Policy, 23(9), 1259-1277. https://doi.org/10.1080/13501763.2016.1225785.

Holcombe, R. G. (2015). Political capitalism. Cato Journal, 35(1), 41-66.

Immerzeel, T., \& Pickup, M. (2015). Populist radical right parties mobilizing 'the people'? The role of populist radical right success in voter turnout. Electoral Studies, 40, 347-360. https://doi.org/10. 1016/j.electstud.2015.10.007.

Jensen, C., \& Bøgeskov Jespersen, B. (2017). To have or not to have: Effects of economics inequality on turnout in European democracies. Electoral Studies, 45, 24-28. https://doi.org/10.1016/j.electstud. 2016.11.009.

Jesuit, D. K., Paradowski, P. R., \& Mahler, V. A. (2009). Electoral support for extreme right-wing parties: A sub-national analysis of western European elections. Electoral Studies, 28, 279-290. https://doi. org/10.1016/j.electstud.2009.01.009.

Karreth, J., Polk, J. T., \& Allan, C. S. (2012). Catchall or catch and release? The electoral consequences of social democratic parties' March to the Middle in Western Europe. Comparative Political Studies, 46(7), 791-822. https://doi.org/10.1177/0010414012463885.

Kelly, N. J., \& Enns, P. K. (2010). Inequality and the dynamics of public opinion: The self-reinforcing link between economic inequality and mass preferences. American Journal of Political Science, 54(4), 855-870. https://doi.org/10.1111/j.1540-5907.2010.00472.x.

Krieger, T., \& Meierrieks, D. (2016). Political capitalism: The interaction between income inequality, economic freedom and democracy. European Journal of Political Economy, 45, 115-132. https:// doi.org/10.1016/j.ejpoleco.2016.10.005.

Kselman, D., \& Niou, E. (2011). Protest voting in plurality elections: A theory of voter signaling. Public Choice, 148, 395-418. https://doi.org/10.1007/s11127-010-9661-2.

Lai, Y.-B. (2010). The political economy of capital market integration and tax competition. European Journal of Poltical Economy, 26, 475-487. https://doi.org/10.1016/j.ejpoleco.2010.02.001.

Lindbeck, A., \& Weibull, J. W. (1987). Balanced-budget redistribution as the outcome of political competition. Public Choice, 52, 273-297. https://doi.org/10.1007/BF00116710.

Lindvall, J., \& Rueda, D. (2013). The Insider-Outsider Dilemma. British Journal of Political Science, 44(2), 460-475. https://doi.org/10.1017/S0007123412000804.

Lohmann, S. (1995). Information, access, and contributions: A signaling model of lobbying. Public Choice, 85, 267-284. https://doi.org/10.1007/BF01048199.

Lubbers, M., Gijsberts, M., \& Scheepers, P. (2002). Extreme right-wing voting in Western Europe. European Journal of Political Research, 41, 345-378. https://doi.org/10.1111/1475-6765.00015.

Mudde, C. (2004). The populist zeitgeist. Government and Opposition, 39, 541-563. https://doi.org/10. 1111/j.1477-7053.2004.00135.x.

Mudde, C. (2013). Three decades of populist radical right parties in Western Europe: So what? European Journal of Political Research, 52, 1-19. https://doi.org/10.1111/j.1475-6765.2012.02065.x.

Myatt, D. P. (2017). A theory of protest voting. Economic Journal, 127, 1527-1567. https://doi.org/10. 1111/ecoj.12333.

Norris, P., \& Inglehart, R. (2019). Cultural backlash. Trump, Brexit, and Authoritarian Populism. https:// doi.org/10.1017/9781108595841.

Noury, A., \& Roland, G. (2020). Identity politics and populism in Europe. Annual Review of Political Science, 23(1), 421-439. https://doi.org/10.1146/annurev-polisci-050718-033542. 
Oesch, D. (2008). Explaning Workers' support for right-wing populist parties in Western Europe: Evidence from Austria, Belgium, France, Norway and Switzerland. International Political Science Review, 29(3), 349-373. https://doi.org/10.1177/0192512107088390.

Pastor, L., \& Veronesi, P. (2021). Inequality aversion, populism, and the backlash against globalization. Journal of Finance, forthcoming. https://doi.org/10.1111/jofi.13081.

Persson, T., \& Tabellini, G. (2002). Political economics: Explaining economic policy. Cambridge: MIT Press.

Pontusson, J., \& Rueda, D. (2010). The politics of inequality: Voter mobilization and left parties in advanced industrial states. Comparative Political Studies, 43(6), 675-705. https://doi.org/10.1177/ 0010414009358672.

Rico, G., Guinjoan, M., \& Anduiza, E. (2020). Empowered and enraged: Political efficacy, anger and support for populism in Europe. European Journal of Political Research, 59(4), 797-816. https://doi. org/10.1111/1475-6765.12374.

Rodrik, D. (2018). Populism and the economics of globalization. Journal of International Business Policy, 1, 12-33. https://doi.org/10.1057/s42214-018-0001-4.

Roemer, J. E. (1998). Why the poor do not expropriate the rich: An old argument in new garb. Journal of Public Economics, 70(3), 399-424. https://doi.org/10.1016/s0047-2727(98)00042-5.

Rooduijn, M. (2017). What unites the voter bases of populist parties? Comparing the electorates of 15 populist parties. European Political Science Review, 10(3), 351-368. https://doi.org/10.1017/s1755 773917000145.

Rooduijn, M., van der Brug, W., \& de Lange, S. L. (2016). Expressing or fuelling discontent? The relationship between populist voting and political discontent. Electoral Studies, 43, 32-40. https://doi. org/10.1016/j.electstud.2016.04.006.

Rydgren, J. (2007). The sociology of the radical right. Annual Review of Sociology, 33, 241-262. https:// doi.org/10.1146/annurev.soc.33.040406.131752.

Schulte-Cloos, J., \& Leininger, A. (2021). Electoral participation, political disaffection, and the rise of the populist radical right. Party Politics, forthcoming. https://doi.org/10.1177/1354068820985186.

Solt, F. (2008). Economic inequality and democratic political engagement. American Journal of Political Science, 52(1), 48-60. https://doi.org/10.1111/j.1540-5907.2007.00298.x.

Solt, F. (2010). Does economic inequality depress electoral participation? testing the schattschneider hypothesis. Political Behavior, 32, 285-301. https://doi.org/10.1007/s11109-010-9106-0.

Solt, F. (2015). Economic inequality and nonviolent protest. Social Science Quarterly, 96(5), 1314-1327. https://doi.org/10.1111/ssqu.12198.

Stadelmann, D., Portmann, M., \& Eichenberger, R. (2015). Income and policy choice: Evidence from parliamentary decisions and referenda. Economics Letters, 135, 117-120. https://doi.org/10.1016/j. econlet.2015.07.022.

Stockemer, D., \& Scruggs, L. (2012). Income inequality, development and electoral turnout-new evidence on a burgeoning debate. Electoral Studies, 31, 764-773. https://doi.org/10.1016/j.electstud. 2012.06.006.

Winter, S. (2017). Symmetric tax competition and lobbying within federations. European Journal of Political Economy, 49, 134-145. https://doi.org/10.1016/j.ejpoleco.2017.02.002.

Publisher's Note Springer Nature remains neutral with regard to jurisdictional claims in published maps and institutional affiliations. 